\title{
Fatores determinantes para inovação: perspectiva de estudantes de Pós-graduação em administração *
}

\section{Determinant factors on innovation: busuness Postgraduate students perspective}

\author{
Juliane Coelho Dias ${ }^{1}$ \\ Cássia Lima Silva ${ }^{2}$
}

\begin{abstract}
Resumo
Estrutura organizacional e liderança são alguns dos fatores que determinam a capacidadede inovação de uma organização. Esses fatores são abordados pelos campos da inovação, filosofia e psicologia. Esta pesquisa teve como objetivo identificar a percepção dos alunos do Programa de Pós-Graduação em Administração (PPGA), da Universidade Federal Fluminense (UFF), em Volta Redonda, a respeito dos fatores de inovação das organizações em que atuam. Utilizou-se como fonte de coleta de dados um roteiro de entrevista semiestruturado e analisaram-se as entrevistas por meio do Discurso do Sujeito Coletivo (DSC). Observou-se que no fator estrutura organizacional não há estímulo à criatividade e as decisões são tomadas em equipe. No fator liderança, o gestor reconhece o desempenho por meios formais e informais e, quando há sugestão de mudanças, por parte dos colaboradores, os gestores buscam aprovação das ideias por intermédio de pares. Em uma das entrevistas, foi possível relacionar a estrutura organizacional e a liderança com a teoria dos objetos transicionais, pela dificuldade de geração de mudanças e aceitação de ideias. Em outra entrevista, foi possível classificar o líder como transformador.
\end{abstract}

Palavras-chave: Capacidade de Inovação. Estrutura

Organizacional. Liderança.

\begin{abstract}
Organizational structure and leadership are some of the factors that determine an organization's innovation capacity. These factors are addressed by the fields of innovation, philosophy and psychology. The aim of the research was to identify the perception of the Postgraduates Management (PPGA-UFF) students at the Fluminense Federal University,in Volta Redonda, about the innovation factors of the organizations where they work. It was used a semi-structured interview script as the source of data collection and the interviews were analyzed through the Collective Subject Discourse (DSC). It was observed that in the organizational structure factor there is no stimulus to creativity and decisions are made as a team. In the leadership factor the manager recognizes the performance by formal and informal ways and when the employees suggested changes, the managers seek approval of the ideas by means of pairs. In one of the interviews, it was possible to relate the organizational structure and leadership with the theory of transitional objects, because of the difficulty of generating changes and accepting ideas. In another interview, it was possible to classify the person as a transformer leader.
\end{abstract}

Key-words: Innovation Capacity. Organizational Structure. Leadership.

\footnotetext{
${ }^{1}$ Administradora e Mestranda no Programa de Pós-graduação em Administração (MPA) na UFF E-mail: juliane.cas@gmail.com

${ }^{2}$ Especialista em Gestão de Negócios e Finança e Mestranda no Programa de Pós-graduação em Administração (MPA) na UFF E-mail: cássia.lima.machado@gmail.com
}

* Artigo apresentado no Congresso de Administração, Sociedade e Inovação (CASI) 2016 


\section{Introdução}

A inovação dentro de uma organização é basicamente uma forma de gerar vantagem competitiva (TAKAHASHI, 2007). Para inovar, as organizações precisam de estrutura e líderes que sejam capazes de aumentar o desempenho das equipes, o poder de colaboração dos subordinados e a promoção do trabalho criativo. Inovar não é apenas inventar novos produtos e serviços, é também desenvolver processos criativos e novas formas de pensamento (BALDAIA, 2013; VALLADARES; VASCONCELLOS; DI SERIO, 2014).

Cada organização é única, possui um conjunto de recursos exclusivos e capacidades internas que fornecem a principal fonte de seus retornos e sua base estratégica. Esses recursos são condição para que as organizações obtenham superioridade de desempenho (BALDAIA, 2013; BARNEY, 1991).

Alguns dos fatores determinantes da capacidade de inovação de uma organização são: liderança transformadora, intenção estratégica de inovar, conhecimento do cliente e do mercado e estrutura organizacional (VALLADARES, VASCONCELLOS; DI SERIO, 2014; GAVA; GARCIA; PAULA; BASTOS, 2015).

O papel dos líderes nas organizações, sejam elas públicas ou privadas, é de fundamental importância, pois os líderes são os "fios condutores" que levarão o desempenho dos colaboradores de encontro ao objetivo e/ou estratégia da empresa.

Para que a inovação ocorra dentro da organização, são necessárias mudanças, mas não é todo líder que é capaz de fomentar essas mudanças. Isso porque suas características pessoais influenciam em seu potencial de levar a mudança adiante em qualquer organização ou até mesmo em sua vida pessoal. O aparelho psíquico e o papel do inconsciente influenciam diretamente no comportamento e atitudes de líderes que permitem ou não que a mudança ocorra (MORGAN, 2006).

Uma organização que possibilita autonomia aos funcionários, colaboração entre os membros, onde a criatividade é vista como uma boa fonte de solução de problemas e melhorias de produtos e processos é fonte de uma estrutura organizacional que também determina a capacidade de inovação de uma organização.

Esta pesquisa teve como objetivo identificar a percepção dos alunos do Programa de Pós-Graduação em Administração da Universidade Federal Fluminense 
(PPGA-UFF), em Volta Redonda, sobre os fatores de inovação das organizações em que atuam, e como resultado do trabalho, foi possível perceber nas falas dos entrevistados tanto a respeito da estrutura organizacional quanto acerca de liderança, que os líderes influenciam (positiva e negativamente) no comportamento das equipes quando o assunto é inovação.

\section{REFERENCIAL TEÓRICO}

\subsection{Mudanças e Inovação}

Toda ação de inovação envolve mudanças. O conceito de inovação remete à introdução de novidade ou aperfeiçoamento em um ambiente social ou produtivo, tendo por resultado novos produtos, processos e serviços (BRASIL, 2004).

A inovação pode ser assumida em quatro formas de mudança: produto, processo, posição e paradigma (BESSANT; TIDD, 2007). A inovação de produto envolve mudanças incrementais ou radicais em bens e serviços, enquanto a outra em processos organizacionais.

A inovação de posição diz respeito a produtos e serviços introduzidos em uma nova realidade (TIGRE, 2006), normalmente ocorre pela introdução de um novo sistema tecnológico, além de ser fonte para a aprendizagem organizacional (ROCHA; VIEIRA, 2016). A mudança de paradigma abrange a mudança de modelos de gestão, enquanto que, para Tigre (2006), a mudança envolve as partes técnica e econômica.

A organização precisa integrar e coordenar recursos para inovar, esse é o conceito de capacidade de inovação. A capacidade de inovação envolve o que a organização está realizando e também o que ela poderá fazer com o objetivo de desenvolver novos produtos, processos ou serviços (TEECE, 2014; VALLADARES, VASCONCELLOS; DI SERIO, 2014). As capacidades de inovação são as capacidades dinâmicas levantadas por Teece (2014) que precisam ser construídas, enquanto as capacidades ordinárias são preestabelecidas e têm ênfase na eficiência.

A pesquisa de Valladares, Vasconcellos e Di Serio (2014) é uma revisão de literatura do conceito capacidade de inovação. Três produtos foram desenvolvidos nesta pesquisa: fatores determinantes e resultantes da capacidade de inovação e uma lista de práticas de gestão. Os produtos servem como um guia para pesquisas empíricas e melhoria da capacidade de inovação das firmas. Alguns dos fatores determinantes encontrados foram: liderança transformadora, intenção estratégica de inovar, 
conhecimento do cliente e do mercado e estrutura organizacional. E fatores resultantes: disposição para mudança, procura de soluções novas e não usuais e desempenho em inovação.

A liderança como fator determinante da capacidade de inovação envolve características de gestores que encorajam mudança, estimulam geração de ideias não usuais para solução de problemas, reconhecem o bom desempenho e buscam compreender os sentimentos de seus funcionários, tal qual defendem Fernandes, Siqueira e Vieira (2014), ao destacarem o papel moderador da liderança. A estrutura organizacional também como fator determinante tem características de uma organização que oferece autonomia aos seus funcionários para solução de problemas e decisões necessárias no dia a dia do trabalho, o trabalho em equipe é estimulado, havendo assim colaboração entre os membros, a criatividade é vista como uma boa fonte de solução de problemas e melhorias de produtos e processos.

Todos os tipos de mudança envolvem as pessoas de alguma forma e para que a proposta seja introduzida no ambiente organizacional, é necessário trabalhar com os fatores determinantes, de modo a gerar maior aceitabilidade e ação por parte dos colaboradores. As proposições de mudança e inovação nas organizações podem ser complexas, pois cada indivíduo é composto por regras e padrões conscientes e inconscientes.

\subsection{O aparelho psíquico e o papel do inconsciente}

A teoria do inconsciente de Freud ajuda a compreender o ser humano, o inconsciente muitas vezes nos guia sem que percebamos. Muitos distúrbios desenvolvidos são consequência de conflitos reprimidos na infância (MEDNICOFF, 2008).

O consciente é todo processo psíquico que temos conhecimento em algum momento (MEDNICOFF, 2008). A dimensão inconsciente é uma estrutura oculta e dinâmica da psique humana, ela é criada a partir do momento que o ser humano reprime desejos interiores e pensamentos secretos (MORGAN, 2006).

$\mathrm{O}$ aparelho psíquico possui as instâncias id, ego e superego. O id é voltado à satisfação de desejos e necessidades do instinto. Seu conteúdo é geralmente inconsciente. A partir do id é que o ego e o superego se desenvolvem. O ego é responsável pela intermediação entre o id e o mundo exterior. O ego controla os

Revista Eletrônica Gestão e Serviços v.8, n. 1, pp. 1811- 1828, Janeiro/Junho 2017. ISSN Online: 2177-7284 e-mail: regs@ metodista.br 
impulsos do id. O superego funciona como sensor, à medida que se respalda em valores morais, ele exerce o papel de dizer que algo é certo ou errado (MEDNICOFF, 2008).

O inconsciente é formado por impulsos reprimidos, para o adulto manter esse reservatório sob controle são utilizados vários mecanismos de defesa. As preocupações excessiva com economia, ordem, regularidade, correção, pontualidade, são tentativas de controlar o mundo exterior, mas refletem na essência uma tentativa de controlar a si mesmo.

\subsubsection{Teoria dos objetos transicionais}

De acordo com a teoria dos objetos transicionais, o ser humano se apega a objetos desde a infância para ser possível distinguir o mundo interior do mundo exterior. De ursos de pelúcia e cobertores na infância passamos a ter apego por ideias, sonhos, talentos e objetos de estimação. Se na vida adulta tivermos um apego rígido por algum objeto, isso poderá bloquear a nossa capacidade de lidar com mudanças no ambiente (MORGAN, 2006).

Os arranjos organizacionais podem ser vistos como fenômenos transicionais à medida que os colaboradores podem depender destes para definir o seu senso de identidade. Se uma mudança for proposta, isso funciona de maneira análoga à retirada do urso de pelúcia de uma criança, o adulto considera inconscientemente uma ameaça à sua própria existência.

A consciência resiste a tudo que é inconsciente e desconhecido, por isso a mudança pode ser tão dificultosa dentro do contexto organizacional. De acordo com Jung (2008), há entre diversos povos primitivos a existência de um medo que os antropólogos chamam de "misoneísmo". Isso significa que o homem se protege com barreiras psicológicas de uma mudança trazida pela inovação.

De acordo com a teoria dos objetos transicionais, o agente de mudança precisa criar fenômenos transicionais, propor um substituto do "objeto" e ter o controle do processo, pois a mudança envolve a identidade de vários indivíduos. Esse cuidado é necessário para evitar o desenvolvimento de mecanismos de defesa grupal que podem ser intensificados pela liderança ou pela estrutura organizacional. 


\subsection{Tipos de liderança}

Segundo Vries e Miller (1990), ainda não se sabe muita coisa sobre o que faz de alguém um bom líder, pois a dinâmica da liderança continua sendo um quebra-cabeça. O que a maioria dos líderes parece ter em comum é a capacidade de despertar emoções primitivas naqueles que os seguem.

Os líderes podem ser classificados em três tipos: carismáticos, onipotentes e transformadores. O líder "carismático" é tratado como se possuísse poderes sobrenaturais e fosse um ser "acima de seres humanos". O líder "onipotente" necessita ser "bajulado", possui alto grau de persuasão e leva o subordinado a sacrificar-se para atender a algum objetivo seu ou loucura pessoal. O líder "transformador" é o líder que desperta os plenos potenciais de seus liderados, estimula a criatividade e acaba transformando os liderados em líderes (FERNANDES, SIQUEIRA; VIEIRA, 2014). A liderança transformadora é a mais utilizada na organização quando o objetivo é inovação.

A liderança dentro das organizações pode ser tanto destrutiva quanto inspiradora, e o que define isso é o estilo de liderança de cada líder. O grau de narcisismo e a origem do líder são primordiais para o desenvolvimento de cada estilo de liderança (VRIES e MILLER, 1990).

A característica narcisista intrínseca do líder faz que este tire vantagem dos outros para satisfazer benefícios pessoais, e o faça incapaz de reconhecer o sentimento dos outros e torne ausente a empatia, pois ele se considera um indivíduo com benefícios especiais, acima dos outros indivíduos.

Os líderes narcisistas são classificados em três tipos, de acordo com as características específicas de cada um (VRIES e MILLER, 1990):

Líder Reativo: são cruéis, grandiosos e exibicionistas; demonstram um desejo de dominar e controlar, sendo extremamente exploradores; procuram subordinados bajuladores; não escutam os subordinados; não admitem os próprios erros; seu mecanismo de defesa o leva a culpar sempre os outros pelos seus erros. 
Líder Autoilusório: são mais doces, menos tiranos e querem ser amados; são obcecados por suas próprias necessidades; possuem um lado discretamente maquiavélico; falta-lhes o sentimento de empatia; são inseguros.

Líder Construtivo: não estão acima de atos ocasionais de oportunismos; têm um alto grau de confiança em sua capacidade; têm uma visão realista de seus limites e capacidades, mesmo gostando de ser admirados; não têm problemas interpessoais por causa da perspicácia de que são dotados e provam isso em suas relações; possuem bom humor e autoconfiança.

Os perfis de liderança determinam como a organização reage a mudanças e, por conseguinte, influenciando sua capacidade de ser inovadora. Os líderes "transformadores" e "construtivos" têm as características necessárias que permitem que a inovação aconteça dentro das organizações que possuem esses tipos de líderes.

\section{MÉTODO}

A pesquisa teve como propósito investigar o seguinte questionamento: Qual a percepção dos alunos do Programa de Pós-Graduação em Administração da Universidade Federal Fluminense (PPGA-UFF), em Volta Redonda, sobre os fatores de inovação das organizações em que atuam?

A relevância da pesquisa está em identificar o contexto organizacional em que os alunos estão inseridos, eles serão futuros líderes ou já são líderes e terão consigo o nome da Universidade.

Para tanto, desenvolveu-se uma pesquisa de caráter qualitativo, quanto à abordagem do problema e, descritivo, quanto aos seus objetivos. Usou-se como fonte de coleta de dados um roteiro de entrevista semiestruturado elaborado a partir da revisão de literatura de Valladares, Vasconcellos e Di Serio (2014). Utilizaram-se os fatores estrutura organizacional e liderança para a elaboração das perguntas.

$\mathrm{O}$ roteiro de entrevista permite ao pesquisador organizar-se antes e no momento da entrevista, esse planejamento está diretamente ligado com a qualidade das informações coletadas. $\mathrm{O}$ roteiro semiestruturado é o ponto inicial da entrevista, no decorrer da mesma o pesquisador pode inserir comentários como "fale mais a respeito 
deste ponto", sem interferir na opinião do entrevistado (MANZINI, 2003; 2012; KAWAUCHE; VIEIRA; MENDONÇA NETO, 2015).

De acordo com Manzini (2003; 2012), o roteiro de entrevista pode ser avaliado por juízes ou entrevista piloto. Os juízes são pesquisadores mais experientes e que de preferência tenham afinidade com o tema pesquisado. Para Gil (2002), essa etapa corresponde ao pré-teste, responsável pela avaliação do instrumento de pesquisa. $\mathrm{O}$ roteiro foi avaliado por cinco juízes e reestruturado com base nos comentários e proposições de melhoria. A seguir, o roteiro de entrevista, após a inclusão de melhorias:

Quadro 1 - Roteiro de entrevista semiestruturado.

\begin{tabular}{|c|c|}
\hline Fatores & Perguntas \\
\hline \multirow{2}{*}{ Estrutura organizacional } & $\begin{array}{l}\text { De que modo os gestores propõem a participação das equipes em } \\
\text { atividades que estimulam a criatividade? }\end{array}$ \\
\hline & $\begin{array}{l}\text { De que maneira a equipe participa nas decisões relativas ao andamento } \\
\text { das atividades por ela desenvolvidas? }\end{array}$ \\
\hline \multirow[b]{2}{*}{ Liderança } & De que forma o gestor reconhece seu desempenho no trabalho? \\
\hline & $\begin{array}{l}\text { Como o gestor conduz as sugestões de mudança feitas por seus } \\
\text { subordinados? }\end{array}$ \\
\hline
\end{tabular}

Fonte: Adaptado de Valladares, Vasconcellos e Serio (2014).

Foram entrevistados dez alunos. As entrevistas foram gravadas com o consentimento dos participantes e foi garantido o sigilo das informações a partir da entrega de um termo de confidencialidade. Para a análise das entrevistas, foi utilizada a técnica do Discurso do Sujeito Coletivo (DSC).

O DSC é a representação de um discurso coletivo a partir de discursos individuais. A técnica levanta as expressões-chave e ideias centrais dos depoimentos individuais tendo por resultado os discursos síntese, que são os Discursos do Sujeito Coletivo. As expressões-chave são trechos dos discursos que revelam a essência do discurso individual. $\mathrm{E}$ as ideias centrais representam de maneira mais sintética as respostas analisadas, dando origem aos DSCs. O Discurso do Sujeito Coletivo é apresentado em primeira pessoa (LEFEVRE; CRESTANA; CORNETTA, 2003; LEFEVRE; LEFEVRE, 2006; FIGUEIREDO, CHIARI; GOULART, 2013). 


\section{RESULTADOS E DISCUSSÃO}

As análises são apresentadas na ordem do roteiro de entrevista, onde cada pergunta é exposta como um tópico. Para facilitar o entendimento, as ideias centrais que mais apareceram nos discursos estão representadas no DSC A. Depois, são mostradas as expressões-chave que compõem esses discursos.

\subsection{Pergunta: De que modo os gestores propõem a participação das equipes em atividades que estimulam a criatividade?}

\subsubsection{Discurso do Sujeito Coletivo}

Quadro 2 -DSCs da pergunta 1

\begin{tabular}{|l|c|}
\hline DSC & Número de pessoas \\
\hline DSC A: Os gestores pouco estimulam ou não estimulam a criatividade. & 7 \\
\hline DSC B: Os gestores desenvolvem atividades que “empoderam” as pessoas. & 3 \\
\hline
\end{tabular}

Fonte: Dados da pesquisa.

O DSC A possui a ideia central que representa o discurso coletivo, pois foi relatada pela maioria dos entrevistados. Os gestores não estimulam a criatividade, mas ainda assim a criatividade aparece em ideias pontuais de alguns colaboradores.

\subsubsection{Expressões-chave das respostas dos sujeitos do DSC A}

Sujeito 1 -Há um tempo não havia estímulo algum, agora o setor da instituição está passando por mudanças. Os gestores começaram a comunicar a necessidade de criação de atividades, mas essas atividades são pouco exploradas.

Sujeito 2 -Não tem muito estímulo a procedimentos novos, criativos. Como as atividades não são formalizadas, é difícil separar a ideia criativa da não criativa, as pessoas fazem as atividades, cada um ao seu jeito. O estímulo a atividades criativas não é uma política da Instituição, não é disseminado em todas as áreas.

Sujeito 3 -Nunca vi qualquer tipo de preocupação relativa à criatividade. A criatividade vem de ideias pontuais de algumas pessoas e não da Instituição ou dos gestores. As ações começam e morrem. Esses tipos de atividades têm que partir do topo da pirâmide Revista Eletrônica Gestão e Serviços v.8, n. 1, pp. 1811- 1828, Janeiro/Junho 2017. ISSN Online: 2177-7284 e-mail: regs@ metodista.br 
para haver aderência e continuidade das atividades.

Sujeito 4 -Na empresa onde trabalho, são poucas as vezes que os gestores estimulam a criatividade.

Sujeito 5 -Não percebo qualquer incentivo à criatividade para qualquer setor.

Sujeito 6 -A criatividade como um todo, na minha área de atuação, é pouco desenvolvida. O mais próximo disso é quando os gestores solicitam que resolvamos problemas mais complexos, que demandam que pensemos um pouco fora do escopo para encontrar a solução.

Sujeito 7 -Eu não vejo muito os gestores onde eu trabalho estimulando a criatividade das equipes. Na verdade, o que é criado atualmente é para poder superar dificuldades que existem hoje no que diz respeito a sistemas de informação, de competitividade, havendo a necessidade de criar algumas soluções para conseguir transpor as barreiras do dia a dia.

\subsection{Pergunta: De que maneira a equipe participa nas decisões relativas ao andamento das atividades por ela desenvolvidas?}

\subsubsection{Discurso do Sujeito Coletivo}

Quadro 3-DSCs da pergunta 2

\begin{tabular}{|l|c|}
\hline DSC & Número de pessoas \\
\hline DSC A: As decisões são tomadas em conjunto. & 5 \\
\hline DSC B: As decisões são centralizadas nos líderes. & 3 \\
\hline DSC C: As decisões em conjunto são poucas ou inexistentes. & 2 \\
\hline
\end{tabular}

Fonte: Dados da pesquisa.

O DSC A - possui a ideia central que representa o discurso coletivo, pois foi a ideia relatada pela maioria dos entrevistados. As decisões são tomadas em conjunto em encontros periódicos.

\subsubsection{Expressões-chave das respostas dos sujeitos do DSC A}

Sujeito 1 -Nos momentos que há possibilidade da decisão ser compartilhada o grupo é reunido e toma decisões em conjunto. Mas há tipos de decisões que não dão para envolver toda a equipe, a decisão deve ser assertiva. Quando você toma uma decisão 
sem envolver o grupo, você perde comprometimento e envolvimento, isso é questão de maturidade.

Sujeito 2 -Com encontros periódicos para a avaliação de cada atividade, assim podemos até mudar a direção da execução de atividades antes propostas pela equipe.

Sujeito 3 -A equipe possui autonomia para propor as ações a serem seguidas. No caso de solicitação de análise de uma solução específica, é possível propor outras soluções que atendam ao objetivo, embora seja necessário apresentar as análises de ambos os casos de forma a possibilitar um comparativo.

Sujeito 4 -Minha gestora é bem flexível e aberta a todo tipo de participação, então nas atividades que desenvolvemos em equipe conseguimos ter um bom andamento e até nós mesmos fazemos o acompanhamento das decisões que tomamos. A equipe tem uma participação muito ativa nas decisões. Operacionalmente falando, a equipe tem uma participação muito boa nas decisões das atividades que desenvolvemos.

Sujeito 5 -Por meio de reuniões semanais, envolvemos todo o time e o seu gestor, com o objetivo de avaliar as principais decisões a serem tomadas para melhor andamento das atividades do grupo e alcance dos objetivos da área. Todo o time avalia o cenário e faz sua recomendação.

\subsection{Pergunta: De que forma o gestor reconhece o seu desempenho no trabalho?}

\subsubsection{Discurso do Sujeito Coletivo}

Quadro 4-DSCs da pergunta 3

\begin{tabular}{|l|c|}
\hline DSC & Número de pessoas \\
\hline $\begin{array}{l}\text { DSC A: Pela confiança no trabalho, autonomia para tomada de decisão, } \\
\text { premiações, feedbacks positivos e indicadores de desempenho. }\end{array}$ & 8 \\
\hline DSC B: O gestor não reconhece meu desempenho. & 2 \\
\hline
\end{tabular}

Fonte: Dados da pesquisa.

O DSC A- possui a ideia central que representa o discurso coletivo, pois foi a ideia relatada pela maioria dos entrevistados. O gestor reconhece meu desempenho por meios formais, como indicadores, avaliações, premiações e também por feedbacks, confiança e autonomia no trabalho. 


\subsubsection{Expressões-chave das respostas dos sujeitos do DSC A}

Sujeito 1 -Quando desenvolvo uma atividade com o meu time que agrega valor para a organização e a gestora fala que aquele trabalho foi bacana. O reconhecimento pode ser tanto por vias informais quanto formais, reuniões realizadas a cada 15 dias.

Sujeito 2 -Falando, elogiando, opinando o que poderia ser diferente. Ele não sabe diferenciar uma ideia criativa da não criativa, mas sabe diferenciar quando uma atividade superou as expectativas do planejado, ele elogia durante as reuniões.

Sujeito 3 -Com a própria confiança depositada na equipe, abertura para interferir nas decisões e autonomia para tomada de decisão.

Sujeito 4 -Alguns reconhecimentos são feitos na festa de fim de ano por meio de premiações.

Sujeito 5 -A maior exposição positiva do trabalho se dá com a execução das ações que trazem a mudança no ambiente de trabalho, estando em segundo plano e métricas relacionadas ao atendimento dos objetivos estabelecidos.

Sujeito 6 -Temos entregas feitas ao final do mês e reportadas a toda a fábrica, então nosso desempenho já fica explícito pelo resultado desses reportes.

Sujeito 7-A melhor forma de identificar como minha gestora reconhece meu trabalho é a confiança que ela deposita em mim, de deixar o segmento sob minha responsabilidade no momento que ela necessita ausentar-se, no momento que ela me dá autonomia para decidir e resolver algumas questões.

Sujeito 8 -Por meio do feedback nas reuniões semanais com o time e durante as reuniões com a alta gestão.

\subsection{Pergunta: Como o gestor conduz as sugestões de mudança feitas por seus subordinados?}

\subsubsection{Discurso do Sujeito Coletivo}

Quadro 5-DSCs da pergunta 4

\begin{tabular}{|l|c|}
\hline DSC & Número de pessoas \\
\hline $\begin{array}{l}\text { DSC A: O gestor busca aprovação de pares ou clientes para implementar as } \\
\text { ideias. }\end{array}$ & 4 \\
\hline DSC B: O gestor é receptivo às ideias. & 4 \\
\hline DSC C: O gestor tenta implementar as ideias. & 1 \\
\hline DSC D: O gestor não é receptivo às ideias. & 1 \\
\hline
\end{tabular}

Fonte: Dados da pesquisa.

Revista Eletrônica Gestão e Serviços v.8, n. 1, pp. 1811- 1828, Janeiro/Junho 2017.

ISSN Online: 2177-7284 e-mail: regs@ metodista.br 
Tanto o DSC A quanto o DSC B tiveram o mesmo número de respondentes. Porém, o DSC A possui a ideia central que representa o discurso coletivo, pois a pergunta enfatiza "como" o gestor conduz as sugestões de mudança, a parte da reação (receptividade) pode ser um dos elementos do processo, mas não discute o como. Quando as sugestões são pertinentes e envolvem decisões além da responsabilidade de aprovação do gestor, ele busca aprovação de pares ou clientes.

\subsubsection{Expressões-chave das respostas dos sujeitos do DSC A}

Sujeito 1 -Os gestores não têm muita autonomia. Se forem mudanças que envolvam apenas as atividades daquele setor, eles até aceitam e conseguem conduzir de forma tranquila. Mas, se forem sugestões que envolvam mudanças de outros setores e dependendo da complexidade, terão de ser submetidas aos acionistas para a aprovação.

Sujeito 2 -Em geral, as sugestões são discutidas de forma a obter consenso, que são influenciadas pelas análises e preferências das partes envolvidas, onde os gestores possuem o poder de decisão.

Sujeito 3 -Mudanças no que diz respeito às nossas operações internas são aceitas e valorizadas de imediato. Quaisquer mudanças mais estratégicas ou que dizem respeito a outros setores demandam tempo e discussão. Algumas vezes, não são levadas adiante, pois não é sempre que a interface com a área em questão é fácil.

Sujeito 4 -Avalia cada sugestão em seu nível de prioridade e de dificuldade de implementação. Realiza um follow-up com as áreas afetadas durante o trabalho em equipe ou nas reuniões de staff.

\section{CONSIDERAÇÕES FINAIS}

As pessoas entrevistadas trabalham em organizações públicas ou privadas, pequenas ou grandes empresas. Sendo assim, os arranjos são variados. É possível perceber nas falas dos entrevistados que os arranjos organizacionais, em sua maioria, não encorajam ou pouco encorajam atividades criativas, porém as decisões são tomadas em equipe. Utilizando a perspectiva de liderança, as falas indicam que o gestor reconhece o desempenho por meio da confiança depositada no trabalho, autonomia para a tomada de decisão, premiações, feedbacks positivos e indicadores de desempenho que 
refletem o resultado da equipe. Foi possível notar que mesmo que a política institucional não estimule atividades criativas, as decisões são tomadas em equipe, porém o gestores buscam sempre a aprovação de pares ou clientes para implementar as ideias sugeridas pelos colaboradores.

É interessante apontar que em alguns casos o arranjo organizacional reflete nas ações dos gestores, a instituição não estimula atividades criativas, as decisões são centralizadas nos líderes ou decisões em conjunto são poucas ou inexistentes, assim o líder é apenas receptivo às sugestões de ideias, não há um processo claro de como as sugestões são conduzidas ou se são mesmo conduzidas.

A estrutura organizacional como fator determinante da capacidade de inovação tem características de uma organização que oferece autonomia aos seus funcionários para a solução de problemas e decisões necessárias no dia a dia do trabalho, o trabalho em equipe é estimulado, havendo assim colaboração entre os membros (VALLADARES; VASCONCELLOS; DI SERIO, 2014). Por meio das entrevistas verificou-se que o trabalho em equipe é estimulado, mas em contrapartida, a criatividade não é vista como uma boa fonte de solução de problemas e melhorias de produtos e processos.

Por isso, as organizações, em sua maioria, atuam nas capacidades ordinárias, ou seja, buscam eficiência para as suas atividades de rotina (TEECE, 2014). As decisões em conjunto são de vital importância para alinhar metas e acompanhar resultados e assim obter eficiência nas atividades. As capacidades dinâmicas são atividades construídas e não preestabelecidas e estão relacionadas a processos de mudança e inovação (TEECE, 2014).

Não há estímulo à criatividade nos arranjos organizacionais, mas ainda assim os colaboradores sugerem mudanças. Os entrevistados podem colaborar para a construção das capacidades dinâmicas, pois levam suas ideias para os gestores que encaminham para a aprovação e possível implementação.

A liderança como fator determinante da capacidade de inovação envolve características de gestores que encorajam mudanças, estimulam geração de ideias não usuais para a solução de problemas, reconhecem o bom desempenho e buscam compreender os sentimentos de seus funcionários (VALLADARES; VASCONCELLOS; DI SERIO, 2014). Por meio das entrevistas verificou-se que muitos gestores apoiam sugestões de mudança, mas não estimulam geração de ideias e 
reconhecem o desempenho por intermédio de opiniões, indicadores, premiações, mas não é possível identificar se buscam compreender os sentimentos dos funcionários.

Foram levantados alguns pressupostos tendo em vista a teoria dos objetos transicionais. Em uma das entrevistas, o arranjo organizacional não estimula a criatividade, as decisões em conjunto praticamente não existem, o líder não reconhece o desempenho, há sugestão de mudanças por parte dos colaboradores, mas nenhuma chega a ser implementada.

$\mathrm{Na}$ teoria dos objetos transicionais, se uma mudança é proposta, isso funciona de maneira análoga à retirada do urso de pelúcia de uma criança, o adulto considera inconscientemente uma ameaça à sua própria existência. Morgan (2006) enfatiza a teoria em detrimento da reação dos colaboradores, por isso o agente de mudança precisa criar fenômenos transicionais, propor um substituto do "objeto" e ter o controle do processo, pois a mudança envolve a identidade de vários indivíduos. Porém, nessa entrevista foi percebido que alguns colaboradores sugerem ideias pontuais, mas a organização e os gestores não aderem às ideias, neste caso o "objeto" pertence aos gestores.

Seguem as falas identificadas concernentes a este assunto: "A criatividade vem de ideias pontuais de algumas pessoas e não da Instituição ou dos gestores. As ações começam e morrem, não há um processo de feedback, um registro. Esses tipos de atividades têm que partir do topo da pirâmide para haver aderência e continuidade das atividades". "Algumas sugestões de mudança chegam até o gestor, mas nos bastidores, são sugestões que não têm peso, não é algo estruturado, não tem equipe de planejamento dentro da Instituição. Falta definição de papéis, as pessoas não sabem o que fazer."

Quanto aos tipos de liderança, foi possível classificar o gestor de uma das entrevistas como líder transformador, aquele que desperta os plenos potenciais de seus liderados, estimula a criatividade e acaba transformando os liderados em líderes (VRIES; MILLER, 1990). Esse gestor estimula a criatividade, questiona decisões e ideias e oferece autonomia. Esse gestor faz parte de um arranjo organizacional que "empodera" as pessoas, um arranjo que estimula processos criativos. Isso não significa que no DSC de arranjo que "empodera" as pessoas (Quadro 2), todos os líderes são transformadores, não foi possível classificar o líder nos dois demais casos. Nas entrevistas, em geral, foi possível identificar que os gestores aceitam as sugestões de 
ideias, ou seja, não são líderes reativos, pois eles escutam os subordinados.

O artigo teve por objetivo identificar a percepção dos alunos do Programa de Pós-Graduação em Administração da Universidade Federal Fluminense (PPGA-UFF), em Volta Redonda, sobre os fatores de inovação das organizações em que atuam. Em uma das entrevistas, foi possível relacionar a estrutura organizacional e a liderança com a teoria dos objetos transicionais, pela dificuldade de geração de mudanças e aceitação de ideias. Em uma das entrevistas, foi possível classificar o líder como transformador (FERNANDES, SIQUEIRA; VIEIRA, 2014). Em linhas gerais, as estruturas organizacionais onde os entrevistados atuam não estimulam a criatividade, mas o gestor reconhece o desempenho por meios formais e informais e quando há sugestão de mudanças por parte dos colaboradores, os gestores buscam aprovação das ideias por meio de pares.

As limitações da pesquisa estão em não classificar os tipos de sugestões de mudança que ocorrem com mais frequência na área de atuação dos entrevistados (Pergunta 4), pois as mudanças podem englobar melhorias nas capacidades ordinárias e/ou também proposições de construção das capacidades dinâmicas.

As limitações também estão no nível de informações obtidas, logo como proposição para pesquisas futuras é interessante utilizar, além de entrevistas, outras técnicas que permitam analisar as barreiras psicológicas que afetam processos de mudança, influência da estrutura organizacional e dos líderes em processos de inovação. É possível haver líderes transformadores em estruturas organizacionais que não incentivam a criatividade? É possível que a estrutura organizacional não seja o suficiente para estimular a existência de lideranças transformadoras? O que mais influencia a geração de novas ideias pelos subordinados, o contexto, a liderança ou a motivação (vista como intrínseca)?

A fenomenologia poderá ser uma das abordagens utilizadas futuramente, pois permite analisar a organização no dia a dia, a interação das pessoas, gestos e falas, por meio de observação não participante (EHRIC, 2005; VIEIRA; RIVERA, 2012), criando possibilidades para analisar barreiras psicológicas no processo de mudança e inovação. 


\section{REFERÊNCIAS}

BALDAIA, J. Intuinovare:a capacidade de inovação ou os recursos disponíveis para inovar. Disponível em:

<http://http://www.josebaldaia.com/intuinovare/inovacao/a-capacidade-de-inovacao-ouos-recursos-disponiveis-para-inovar.htm> Acesso em: dezembro de 2015.

BARNEY, J. Firm resources and sustained competitive advantage. Journal of Management, v.17, n.1, p.99-120, 1991.

BESSANT, J.; TIDD, J. Inovação e Empreendedorismo. Porto Alegre: Bookman, 2007.

BRASIL. Lei n. 110.973, de 2 de dezembro de 2004. Dispõe sobre incentivos à inovação e à pesquisa científica e tecnológica no ambiente produtivo e dá outras providências. Disponível em: <http://www.planalto.gov.br/ccivil_03/_ato20042006/2004/lei/110.973.htm> Acesso em: julho de 2015.

EHRICH, L. C. Revisiting phenomenology: it's potential for management research. In: Proceedings Challenges or organizations in global markets. British Academy of Management Conference. Said Business School, Oxford University, 2005.

FERNANDES, C. M.; SIQUEIRA, M. M. M.; VIEIRA, A. M. Impacto da percepção de suporte organizacional sobre o comprometimento organizacional afetivo: o papel moderador da liderança. Revista Pensamento Contemporâneo em Administração, v. 8, n. 4, p. 140-162, 2014.

FIGUEIREDO, M.Z.A., CHIARI, B.M.; GOULART, B.N.G. Discurso do Sujeito Coletivo: uma breve introdução à ferramenta de pesquisa qualiquantitativa. Revista Distúrbios da Comunicação, v. 25, n.1, p. 129-136, 2013.

GAVA, R.; GARCIA, M. O.; PAULA, P. F.; BASTOS, T. B. Inovação Tecnológica e Desenvolvimento Local: Spin-offs Acadêmicas diante de um Quadro Que Conjuga Dinamismo Científico e Estagnação Econômica. Revista Organizações em Contexto, v. 11, n. 21, p. 211-239, 2015.

GIL, A.C. Como elaborar projetos de pesquisa. São Paulo: Atlas, 2002.

JUNG, C. G. O homem e seus símbolos. Tradução de Maria Lúcia Pinho. Rio de Janeiro: Nova Fronteira, 2008.

KAWAUCHE, R.; VIEIRA, A. M.; MENDONÇA NETO, O. R. Relações interpessoais e atuação profissional: A perspectiva dos contabilistas. Revista Eletrônica Gestão e Serviços, v. 6, n. 2, p. 1.289-1.314, 2015.

LEFEVRE, A.M.C., CRESTANA, M.F. e CORNETTA, V.K. A utilização da metodologia do discurso do sujeito coletivo na avaliação qualitativa dos cursos de 
especialização "Capacitação e Desenvolvimento de Recursos Humanos em SaúdeCADRHU”. São Paulo, 2002. Revista Saúde e Sociedade, v. 12, n.2, p.68-75, 2003.

LEFEVRE, F.; LEFEVRE, A. M. C. O sujeito coletivo que fala. InterfaceComunicação, Saúde, Educação, v. 10, n. 20, p. 517-524, 2006.

MANZINI, E.J. Considerações sobre a elaboração de roteiro para entrevista semiestruturada. (In:) Maria Cristina Marquezine, Maria Amélia Almeida, SadaoOmote (Orgs.). Colóquios sobre pesquisa em educação especial. Londrina: Eduel, 2003.

MANZINI, E.J. Uso da entrevista em dissertações e teses produzidas em um programa de pós-graduação em educação. Revista Percurso - NEMO. Maringá, v.4, n. 2, p. 149$171,2012$.

MEDNICOFF, E. Dossiê Freud. São Paulo: Universo dos Livros, 2008.

MORGAN, G. Imagens da Organização. São Paulo: Atlas, 2002.

ROCHA, A. F. R.; VIEIRA, A. M. Aprendizagem Organizacional e Inovação de Produtos: estudo em Empresas de Base Tecnológica do Vale da Eletrônica (MG). Caderno Profissional de Administração da UNIMEP, v. 6, n. 1, p. 108-131, 2016.

TAKAHASHI, S. Gestão da inovação em produtos: estratégia, processo, organização e conhecimento. Rio de Janeiro: Elsevier, 2007.

TEECE, D. J. The Foundations of Enterprise Performance: Dynamic and Ordinary Capabilities In An (Economic) Theory of Firms. Academyof Management Perspectives, v. 28, n. 4, p. 328-352, 2014.

TIGRE, P. B. Gestão da Inovação: a economia de tecnologia do Brasil. Rio de Janeiro: Campus, 2006.

VALLADARES, P. S. D. de A; VASCONCELLOS, M. A. de; SERIO, L. C. Di. Capacidade de inovação: Revisão Sistemática da Literatura. Revista de Administração Contemporânea. Rio de Janeiro,v.18, n. 5, p. 598-626, 2014.

VIEIRA, A. M.; RIVERA, D. P. B. A Hermenêutica no Campo Organizacional: duas possibilidades interpretativistas de pesquisa. Revista Brasileira de Gestão de Negócios, v. 14, n. 44, p. 261-273, 2012.

VRIES, M. FR; MILLER, D. Narcisismo e liderança: uma perspectiva de relações de objetos. Revista de Administração de Empresas, v. 30, n. 3, p. 5-16, 1990. 